\title{
Carl Einstein editor de contos e lendas - todos os caminhos levam à África
}

Carl Einstein editor of legends and tales - all paths lead to Africa

Maria Aparecida Barbosa

UFSC

Yeo N'gana

Université Félix Houphouët Boigny, Costa do Marfim 


\section{Resumo}

Apresentação concernente a movimentos que perfazem as narrativas tradicionais africanas. Essa ficção e esse imaginário em mobilidade desempenham papel fundamental na constituição da cultura brasileira. Este ensaio estuda a metodologia e as estratégias eleitas pelo escritor judeu alemão Carl Einstein (1885-1940), na transcriação dos contos e lendas africanos à língua alemã e na respectiva edição da coletânea Afrikanische Märchen und Legenden (1925). A título de ilustração, apresentamos no final a tradução ao português de alguns dos contos africanos que a integram. Editor também de várias revistas modernistas, colaborou, entre outras, com Die Aktion, Der blutige Ernst, Pleite, Die Opale, Zenit e, de 1929 a 1931, dirigiu a Documents de Paris, editando-a com George Bataille, Georges Henri Rivière e Michel Leiris, revista em que ele concretizou a guinada antropológica de suas pesquisas. Dentro de sua obra, importa salientar Plástica Negra [Negerplastik] e A Arte do Século 20.

Palavras-chave: Carl Einstein; Afrikanische Märchen und Legenden; transcrição; tradução; mobilidade

\section{Abstract}

Movements that perform traditional african narratives transcribed in german. The aim is to think about the displacement of this fiction and this imaginary even to the brazilian reception. In the framework of the article, what is mainly being analyzed is the work of Carl Einstein (1885-1940), a german jewish writer who edited several modernist magazines. He collaborated, among others, with Die Aktion, Der blutige Ernst, Pleite, Die Opale, Zenit and, in Paris from 1929 to 1931, he directed Documents, and edited it with George Bataille, Georges Henri Rivière and Michel Leiris, and in which he turns of his research anthropologicaly. Within his work, for the purposes of this study, it is important to highlight the edition of Plástica Negra [Negerplastik] and The Art of the 20th century. As an illustration, the article presents three of the african tales, in translation to Portuguese.

Keywords: Carl Einstein; Afrikanische Märchen und Legenden; transcription; translation; mobility 


\section{Introdução}

Para além da herança oral trazida diretamente pelos africanos que se estabeleceram no Brasil, uma via indireta dessa cultura narrativa acontece no século XX via edições bibliográficas preparadas por Blaise Cendrars, Carl Einstein e outros escritores modernistas europeus.

Recentemente foi descoberto no porão de um casarão colonial da cidade histórica de Ouro Preto um painel de desenhos gravados na parede em baixo relevo com ilustrações de cenas africanas. Outrora uma senzala, o porão escuro estava atravancado com móveis que não permitiam acesso à parede coberta de imagens, até que um pedreiro chamou a atenção do proprietário para os desenhos. Configuram duas personagens femininas viajando no mar a bordo de um navio, situações cotidianas em que mulheres socam o pilão e esboços de animais domésticos. A voz do escravo africano anacronicamente manifestando, nessa forma, o universo de seu pensamento criador e o doloroso banzo. Se confirmada a hipótese de que se trata efetivamente de desenhos realizados no século XVIII, é uma inédita descoberta estética no Brasil.

A presentificação desses desenhistas de Ouro Preto suscita indagações acerca dos extraordinários caminhos, às vezes, enviesados, que a arte africana traçou na mobilidade dos seus desdobramentos. Acentuar e valorizar a herança cultural de matriz africana faz-se mais que nunca mister quando tem lugar até mesmo uma tendência a negar a veracidade histórica da escravidão ${ }^{1}$ o país recebeu o considerável contingente de 4,8 milhões de africanos, dos 10 milhões que vieram para as Américas. ${ }^{2}$

1 O tunisiano Albert Memmi, que às vezes foi qualificado como escritor de conteúdos panfletários, mas cuja atualidade e agudeza constatamos, escreve no prefácio da edição 1966 do opus magnum Retrato do colonizado precedido de retrato do colonizador: "Não vemos até os dias de hoje algumas descolonizações se efetuarem de maneira tão penosa porque o ex-colonizador não renuncia de fato a seus privilégios, e tenta dissimuladamente reavê-los? O privilégio colonial não é unicamente econômico". (MEMMI, Albert. Retrato do colonizado precedido do retrato do colonizador, 2007, p. 17-22). No convívio entre o colonizador e o colonizado, o esmagamento e a humilhação cotidiana do colonizado vão além desse aspecto. "Em vez de irritar-se com os propósitos dos escritores, e de acusá-los de semeadores da desordem, seria melhor ouvi-los mais atentamente e levar a sério suas advertências premonitórias". (Ibidem).

2 Faz-se necessário investir no combate a essa recusa categórica quanto à responsabilidade do Brasil no tráfico de africanos. $\mathrm{O}$ valor de cunho estético dessas narrativas deve ser ideorelacional (visando otimizar as forças intelectuais, físicas, espirituais, econômicas e político-sociais) e menos ideoracional (que negando os fatos históricos, parte de projeções fortalecidas por ludibriações garantidoras de status quo e privilégios). "Afirmar que o mundo é plural, militar por sua declosão, significa dizer que a Europa não é o mundo, mas apenas parte dele. (MBEMBE, Achille. Crítica da razão negra, p. 273). “[...] A celebração da alteridade somente tem sentido se se abrir para a questão crucial do nosso tempo, a questão da partilha, do comum e da abertura à exterioridade.” (Ibidem, p. 305). É aí que se deposita o peso da História. "Quase ninguém quer enxergar a conexão entre o colonialismo de outrora e a injustiça social global contemporânea”. (RAUTERBERG, Hanno. “Ab ins Museum!”, 2020, p. 39). 
Há toda uma ideologia construída, inclusive de fundo religioso, para dizer que os africanos eram selvagens, bárbaros, pagãos, praticantes de religiões demoníacas, e que portanto a melhor coisa que poderia acontecer com o africano era ser escravizado para se incorporar a suposta civilização europeia que se instalava nos trópicos. Era muito comum nas discussões do parlamento brasileiro a ideia de que a escravidão era a redenção dos escravos. O Padre Antônio Vieira, no final do século 17, defendia a ideia de que era uma graça divina que os escravos tivessem tido a oportunidade de serem escravizados para se incorporar à Igreja Católica. ${ }^{3}$

A escritora brasileira Ruth Guimarães, que coletou Contos Negros "na fonte, isto é, entre o povo, assim como quem recolhia ouro, no tempo em que o havia", afirma que essas narrativas são variantes das tradições orais transcritas por Grimm, Andersen, Perrault, a maioria das narrativas tradicionais do Brasil vêm das recontações dos portugueses, europeus que cá se estabeleceram com vistas à colonização. ${ }^{4}$ Somamse as lendas ameríndias e as africanas. Sua seleção não considerou com rigor a origem africana, considerando que "muitos contos dos bantos, nagôs e jejes são histórias europeias recontadas pelos negros". O seu "garimpo" de narrativas foi a região valeparaibana:

\footnotetext{
Região onde viveu e vive um povo que, depois da Bahia, tem a maior influência negra no Brasil: Sul de Minas, Sudoeste de São Paulo e Baixada Fluminense (Vale do Paraíba mineiro/ paulista/papa-goiaba). Compõem um triângulo de incidências de costumes e de folclore negro, condicionado primeiro pela antiga proximidade do empório do Rio de Janeiro, onde se mercadejava a carne humana para o trabalho: lavoura do algodão, do café e a grande aventura da garimpagem. ${ }^{5}$
}

Essa mobilidade cultural sucede em sentidos mútuos, contíguos, intrincados, como vasos comunicantes porosos.

Os escritores europeus buscavam fontes estéticas africanas, evidenciando o mal-estar da modernidade quanto ao seu presente marcado por imperialismo e guerra, o que perturbava tanto a remissão à tradição quanto a construção de uma instância

3 GOMES, Laurentino, 2019, "Infelizmente, a história da escravidão é contada por pessoas brancas", $\mathrm{s} / \mathrm{p}$.

4 GUIMARÃES, Ruth. Contos negros, 2020, p. 2.

5 Ibidem, 2020 p. 3. 
de porvir. ${ }^{6}$ Por volta de 1908, na Europa, deflagra a insatisfação dos artistas com as convenções pictóricas. Picasso é um dos primeiros a estudar os princípios formais técnicos da arte africana. Os artistas constatam que o objeto definido era um mito: podia-se abrir os objetos como se abre uma caixa e eleger elementos para o quadro; e a literatura passa a recortar o tempo literário que desavém com o tempo prático. ${ }^{7}$ Carl Einstein e Blaise Cendrars, no tempo da crise, abandonaram como desertores as convenções da tradição estética e pesquisaram visões estrangeiras.

\section{O lirismo das narrativas africanas via Cendrars}

O escritor franco-suíço Blaise Cendrars teve uma ligação forte com o Brasil, país que conheceu por intermédio de seus amigos artistas modernistas paulistas no ano de 1924, quando viu o carnaval carioca, visitou as cidades históricas mineiras, seguiu para Belo Horizonte, onde encontrou escritores ${ }^{8}$, e a partir daí desencadeou um mundo de conexões e ficções, que se irradiavam também de maneira bem inspiradora entre amigos escritores, pintores, cinegrafistas etc., e que repercute até hoje, conforme comprova artigo de Carlos Calil na Folha de São Paulo no dia 23 de janeiro de 2021 "Quem foi Blaise Cendrars, franco-suíço que se encantou por Aleijadinho e influenciou Oswald e Tarsila”. Blaise Cendrars retornou, em 1926 e em 1927 (não há comprovação de posteriores viagens que ele afirma ter feito), à terra que inspirou seus escritos e filmes, conforme apresenta Alexandre Eulalio na minuciosa pesquisa que foi revista por Carlos Augusto Calil para a segunda edição: $A$ aventura brasileira de Blaise Cendrars.

6 Se tais escritores europeus se davam conta do eurocentrismo, é de se perguntar o que pensariam os africanos sobre a imposição cultural. Em uma publicação post-mortem da revista Africulture, Jean-Marie Adiaffi vinha elaborando um texto fundador, cuja meta era federar as religiões e/ou culturas africanas. A seu ver, a colonização ocorreu pela imposição da cultura ocidental, pela negação pura e simplesmente da cultura do "Outro" e, principalmente, pelo mandamento manu militari das religiões vindas da Europa. No entender de Adiaffi, se é que existe uma trilha rumo à libertação, ela deve passar compulsoriamente pela religião, por meio das mesmas táticas que as que nos foram impostas. "O mal-estar", melhor dizendo, o "não estar" conduz inexoravelmente a "não Ser". O que vale uma alma que nem sabe identificar seus símbolos, seu nome, sua religião? Um estrangeiro para si mesmo, um rosto inominável. ADIAFFI, Jean-Marie. "Le pluriethnisme est une richesse si les gens n’ont pas honte de parler leur langue", 2003, p. 74-77.

7 EINSTEIN, Carl. Documents: 1929 / Carl Einstein, 2016, p. 41.

8 "A história dos modernistas mineiros foi objetos de incontáveis depoimentos e crônicas, das quais a mais notável e minuciosa é a de Pedro Nava, no quarto volume de suas memórias, intitulado Beira-mar. De acordo com esses testemunhos, em fevereiro de 1922, eles nem chegaram a tomar conhecimento da Semana de Arte Moderna ( e não havia aí arroubo de originalidade ou mentira, pois na época só chegavam a Minas os jornais do Rio de Janeiro, que não deram destaque ao acontecimento). Em compensação, tiveram a oportunidade de viver uma segunda Semana em abril de 1924, quando passou por Belo Horizonte a caravana de paulistas que tinha ido visitar as cidades históricas, em companhia do poeta franco-suíço Blaise Cendrars.” (MARQUES, Ivan. Modernismo em Revista, 2013, p. 51). 
Por ocasião de sua primeira estada em São Paulo, no dia 28 de maio de 1924, profere uma conferência de interesse geral intitulada "A literatura negra", no ensejo de sua bem-sucedida antologia:

Fiz minha Anthologie nègre compulsando 1180 volumes na Biblioteca Nacional e me apoiando em gramáticas, dicionários, contos compostos pelos missionários e por eles trazidos da África desde 1815. Missionários ingleses, franceses, alemães, dos pequenos povos protestantes do norte da Europa, mais tarde americanos, todos sofreram influência do ambiente negro a ponto de aprender as línguas de África, de traduzir, apesar dos seus rudes trabalhos de proselitismo, os contos que os negros se contam à noite em torno dos fogos das suas aldeias, de trazer à Europa, de imprimi-los às próprias custas. Quer dizer, toda a virtude da literatura negra. O que caracteriza o conjunto da literatura negra é o seu lirismo. O lirismo é uma maneira de ser e de sentir. Sabemos que a língua é o reflexo da consciência humana. A literatura dá a conhecer a imagem do espírito que a concebe. ${ }^{9}$

Alexandre Eulalio ressalva que, na conferência Cendrars, não aproximou o mundo cultural e linguístico do negro africano ao do brasileiro que acabava de conhecer. Em 1928, ele edita poeticamente textos que não empregara na Anthologie, direcionandoos ao público mais jovem num novo livro. ${ }^{10}$ Esse livro Petits contes nègres pour les enfants des blancs foi editado pela L\&PM em 1989 com o título literal - Pequenos contos negros também para crianças brancas, tradução de Ana Maria Lisboa de Mello. Atualmente está disponível no mercado brasileiro a Edições SM de 2014, com a tradução de Priscila Figueiredo.

Cottier pressupõe, em "Blaise Cendrars et Carl Einstein: l' alternative africaine d' un début de siècle“, que, em suas relações com o mundo germânico anteriores à Primeira Guerra Mundial ou posteriores, Cendrars já convivera com Carl Einstein. Parece certo. Pois, em carta de 22 de dezembro de 1930, remetida de Biarritz ao seu amigo brasileiro Paulo Prado, Cendrars recorda Carl Einstein: "Ainda estou na nossa última ida à Coupole (como se desde então a Terra não tivesse girado mais que um relógio parado) e vejo ainda Einstein, feio, suas mulheres, feias, seu cunhado, a cabeça raspada, feio etc. etc. e isso não me dá nenhuma vontade de voltar a essa Paname de luxo!"11

Há um século, na década de 1920, o ambiente intelectual vibrante, tanto na Europa como nos centros urbanos importantes do Brasil, propiciava o desejo dos intercâmbios e do conhecimento de manifestações criativas de outras naturezas.

9 EULALIO, Alexandre, A Aventura brasileira de Blaise Cendrars, 2001, p. 131.

10 CALIL, Carlos Augusto. "Preto no Branco", 2014, p. 8.

11 EULALIO, Alexandre, A Aventura brasileira de Blaise Cendrars, 2001, p. 207. 
Ivan Goll escrevia poemas como "O negro do teatro de variedades", traduzia as brasilianidades de Cendrars ao alemão, traduzia os poemas e as preces africanas transcritas por Carl Einstein ao francês, editava essas novidades de proveniências diversas em livros com escritores do mundo inteiro, através de Cendrars, conhecia os brasileiros Sérgio Milliet, Mário de Andrade.

\section{Carl Einstein editor de lendas e contos}

Durante o Imperialismo na África, missionários, linguistas e etnólogos realizavam estudos de campo e transcreviam contos e lendas que lhes eram narrados oralmente. Provavelmente devido ao livro Escultura Negra ${ }^{12}$ que lhe rendera fama de connaisseur da estética africana, o escritor judeu alemão Carl Einstein (1885-1940) que, em 1915, durante a Primeira Guerra Mundial, era recruta voluntário estacionado na Alsácia, foi transferido como responsável pela administração colonial a Bruxelas em 1916. ${ }^{13}$ Aos seus pesquisadores e biógrafos a transformação de combatente voluntário a revolucionário comunista na Bélgica do final da guerra, em 1918, é em parte um mistério. Roland seleciona um fragmento do espólio que comprova seu entusiasmo inicial com a guerra:

\footnotetext{
No sábado dia 8 de agosto, eu me postava às 5 horas em frente à Franzerkaserne. Às 8 horas, estava diante do oficial que selecionava os voluntários. O senhor é um pouco velho, aguarde informações de sua unidade de Landsturm. Passei pela revista e me consideraram adequado. Às 12 horas, estava de uniforme. Com meus camaradas. [...] Passamos a integrar uma nova comunidade: pessoas que queriam morrer ou vencer juntas. ${ }^{14}$
}

Mas, contrapõe o entusiasmo a um trecho da carta que ele remete em 1917 à esposa, na qual já confessa enorme desilusão: "nesta noite, os tiros foram terríveis. Fiquei a noite inteira sentado, urrando, gemendo, chorando. Assim são minhas noites. [...] Não aguento mais a guerra. Tudo está se desmoronando; tudo que eu prezava está destruído."

Desde, portanto, sua transferência para Bruxelas e seu acesso ao acervo de documentos coloniais belgas, que se encontravam abrigados no Africa Museum em Tervuren nas imediações da capital, Carl Einstein inicia o empreendimento das primeiras transcrições de lendas e contos africanos.

12 Negerplastik. Leipzig: Editora Weissen Bücher, 1915. Edição brasileira: Negerplastik. [Escultura Negra]. Florianópolis: Ed. UFSC, 2011.

13 ROLAND, Hubert. Die deutsche literarische "Kriegskolonie" in Belgien, 1914-1918, 1999, p. 62-63.

14 Ibidem, p. 63. 
Esse gênero de antologia parte de documentações - escritas em francês, raramente em inglês ou em traduções alemãs - da literatura oral africana. Como desconhecia línguas africanas, Carl Einstein pesquisava estudos etnológicos ou missionários em francês e os adaptava poeticamente ao alemão. Uma metodologia que indicia aproximação bem relativa com o estrangeiro, mas que pode ser atenuada pelo discernimento empírico, conforme ponderamos. A antropologia cultural, com Franz Boas e outros autores, viria postular a compreensão das sociedades chamadas primitivas a partir de "categorias nativas" de pensamento, conhecimento das línguas etc. Caso bem diferente é o da antologia de referência do auge do nacional-socialismo - publicada em 1940 pela Essener Verlaganstalt, editora que se tornou conhecida como a editora doméstica de Hermann Göring - e que leva ao extremo o distanciamento em relação ao retratado. ${ }^{15}$ Organizada por Diedrich Westermann, Diretor do Seminário para Línguas Orientais (SOS) da Universidade de Berlim desde 1921, fez jus a subsídios da ditadura a pesquisas sobre colonialismo alemão e africanismo, que beneficiavam pesquisadores africanistas politicamente conservadores ou pactuados com o partido.

Os próprios provedores dos textos já se inclinam à adaptação nas transcrições, versões interlineares, traduções ou até recontações por meio de concepções europeias, moralistas e estilísticas. Como as ideias dos missionários e oficiais coloniais - também dependendo da geração - eram consideravelmente mais convencionais, mais antiquadas do que as dos poetas vanguardistas e boêmios em questão [Einstein, Cendrars, Tristan Tzara], o processamento de texto pode ter tido um efeito corretivo às vezes: "Arte" correspondia à falta de confiabilidade do significado cultural estrangeiro. ${ }^{16}$

15 Mesmo não tendo noção suficiente das línguas faladas no Togo, Westermann organiza a antologia intitulada Africanos contam suas vidas: onze autorretratos de nativos africanos de todos os niveis de educação e profissões $e$ de todas as partes da Africa [Afrikaner erzäblen ihr Leben: Elf Selbstdarstellungen afrikanischer Eingeborener aller Bildungsgrade und Berufe und aus allen Teilen Afrikas]. Havia uma tendência naquele período de promover pesquisas nas colônias que mostrassem ao povo alemão formas inéditas que, todavia, em nada transformassem o cenário da relação. Escrever histórias de vida granjeava reconhecimento acadêmico e essa audácia de apresentar biografias africanas foi amplamente saudada no auge do nazismo. $\mathrm{O}$ que aqui incomoda encontra explicação em Claude Lévi-Strauss: [...] o círculo intransponivel: quanto menos as culturas bumanas podiam comunicar-se entre si e, por consequência, corromper-se pelo contacto, menos também os seus respectivos emissários eram capazes de perceber a riqueza e a significação dessa diversidade. [...] (LÉVI-STRAUSS, Claude. Tristes Trópicos, 1957, p. 38). Consciente dessa enfermidade, ele se afetava com os detalhes que via e se censurava sem cessar por não olhar suficientemente. Apesar da declarada empatia (Einfühlung), Westermann decerto não escapa da enfermidade a que Lévi-Strauss se refere nas entrelinhas: o "etnocentrismo europeu" dentro do qual são formados tantos pesquisadores e que impede uma compreensão mais sutil no encontro com outrem.

16 KIEFER, Klaus, Diskurswandel Im Werk Carl Einsteins, 2015, p. 144. 
Kiefer indica que Carl Einstein também demonstra um procedimento ambíguo em suas adaptações. Se, por um lado, preza a arte africana e nessa estima se atém, por outro lado, contradiz sua intenção etnológica ao lidar intervindo nos textos modelos com seu habitual estilo abreviado. Contraditórios seriam também os seguintes procedimentos estilísticos: uso de arcaísmos - lexical, morfológico, sintático, principalmente da linguagem bíblica, como por exemplo, "reconhecer" por "testemunhar" e empregos de registros acentuadamente coloquiais. A atitude vanguardista de Carl Einstein, arbitrária como as dos provedores intermediários, estaria todavia coincidindo com o cuidado que Derrida observa em certas confissões etnográficas preliminares, a que se deve atribuir legitimidade empírica, uma vez que se propõem a denunciar a fragilidade do discurso eurocêntrico. ${ }^{17}$

Esse desafio à hegemonia do etnocentrismo se manifesta à maneira de um descentramento autoral e editorial do livro dos contos e lendas africanos. O autor real ou empírico é considerado a variável mais importante para a interpretação dentro das concepções positivistas, hermenêuticas, psicanalíticas e existencialistas. Essas abordagens foram posteriormente tornadas mais precisas, na medida em que a ideia de autor é relativizada como um fator de atuação integrado social ou linguisticamente. Outras teorias de interpretação renunciam ao elemento autor na análise e se voltam mais ao texto e ao leitor como referências.

Notadamente autônomos são apresentados os textos da coletânea editada por Carl Einstein em comparação com similares organizadas por seus contemporâneos. Leo Frobenius (1873-1938) era a referência, em virtude de suas dispendiosas viagens à África, e a publicação, entre outros livros, de Das schwarze Dekameron: Geschichten aus Afrika (o Decameron negro: contos da África) que Jakob Schaffner (em Neue Rundschau 1 1911, p. 119-123) deplorou por requisitar demasiadamente pressupostos literários europeus o que o próprio título já implicita.

Afrikanische Märchen (1917), que o Pastor Carl Meinhof (1857-1944) publicou “dedicado aos bravos homens e mulheres alemães", pertencia à mesma coleção da Editora Diederichs de Indianermärchen aus Südamerika (1920) de Theodor KochGrünberg $^{18}$. Linguista reconhecido devido às gramáticas comparativas de línguas

17 Derrida se refere às descrições das afecções empíricas do sujeito - os Nhambiquara - que Lévi-Strauss introduz ao falar dos atributos "bondade" ou "inocência", antes de proceder à intrusão da violência e da escritura teóricas. "Descartes ou Husserl nunca teriam deixado entender que considerassem verdade de ciência uma modificação empírica de sua relação ao mundo ou a outrem, nem premissa de um silogismo a qualidade de uma emoção.” (DERRIDA, Jacques. Gramatologia, 2004, p. 145).

18 Os estudos sobre a mitologia, as lendas, a etnologia, a antropologia e histórias dos povos indígenas da América do Sul, sobretudo dos povos indígenas brasileiros da região Amazônica, que foram realizados pelo etnologista e explorador Theodor Koch-Grünberg, serviram de inspiração para a composição do livro de Mário de Andrade, Macunaíma, o herói sem nenhum caráter (1928). 
bantus, bem como aos estudos sobre a língua herero, Carl Meinhof desenvolveu também teorias linguistas antisemitas. E seu livro Die Christianisierung der Sprachen Afrikas (a cristianização das línguas da África) sugeria capciosamente aos missionários que encontrassem palavras existentes nas línguas africanas, que fossem suscetíveis a modificações morfológicas dos afixos e buscassem flecti-las ao sentido cristão. ${ }^{19}$

Desde as atuações precursoras de Tristan Tzara (1896-1963) e Antonin Artaud (1896-1948), várias gerações de escritores e intérpretes vêm se aproximando de uma extensa gama de culturas outrora impenetráveis em todo o mundo e interagindo com essas poéticas por meio do fazer poético experimental, por meio de criativas abordagens de linguagem e performance: o que Rothenberg denomina etnopoesia. Para ele, a proposta de organizar antologias históricas com inclinação etnopoética visa "reconfigurar o passado poético do ponto de vista do presente". ${ }^{20}$

Pensando na reversão de uma lógica colonialista, indagamos se as leis curadoras que configuram estilisticamente Negerplastik [Escultura Africana], publicado pela Ed. UFSC em 2011, poderiam ser observáveis na coletânea literária de 1925 que Carl Einstein igualmente editou? Seria possível fazer tal analogia e pensar o modus operandi de Carl Einstein? Na resenha "Und Afrika sprach...", de 1915, Huebner ousou traçar o paralelo entre a coletânea homônima de narrativas (de Frobenius) e Negerplastik. Ele ponderou que enquanto o escultor africano operaria revelando em sua maneira de representação uma concepção espacial convincente como raramente se encontra em outros povos, pois, graças à invenção da espacialidade bidimensional, as ideias são montadas na superfície, a fábula também deveria se organizar de maneira que uma gama de indicadores fosse exposta, deixando a compreensão a cargo do leitor ou ouvinte. Semelhantemente, essa autonomia é defendida na resenha de Hausenstein. Ele diz que a escultura africana contrapõe-se à plástica europeia porque exclui o conceito europeu de subjetividade. No caso dos artistas europeus, tudo era então projeção. A escultura consistia mais em confirmações de uma gênese do que de uma forma objetivada. No caso dos artistas africanos, a atividade do homem operando na arte suspendia na configuração tudo o que concerne a interpretação, psicologia, óptica, estética. "Surge a coisa formal - não a obra. É por essa razão que Einstein chama a arte negra de 'realismo formal' (formaler Realismus).” [...] "Necessariamente resulta disso, quando não se tem a projeção nem imagem tridimensional nem se almeja transformação ótica-perspectiva ou coisa que o valha, uma grande autonomia das parcelas. A forma específica vive."21

19 MEINHOF, Carl. Die Christianisierung der Sprachen Afrikas, 1905, p. 3-10.

20 ROTHENBERG, Jerome. Etnopoesia no milênio, 2006, p. 225.

21 HAUSENSTEIN, Wilhelm. "Negerplastik", 1915, p. 103. 
Ou seja, o que a princípio leva a pressupor diletantismo ou negligência metodológica evidencia-se como critério operacional sopesado no sentido de evitar ao máximo tolher a autonomia dos objetos. A ausência das referências concretas e dos prefácios subjetivos circunstanciados abre, assim, as vias rumo às referências imaginárias ${ }^{22}$, não metafísicas, mas sim profanas, específicas do leitor, do ouvinte.

\section{Referências bibligráficas}

ADIAFFI, Jean-Marie. "Le pluriethnisme est une richesse si les gens n'ont pas honte de parler leur langue". Africultures, n. 56, v. 3, 2003, p. 74-77. Disponível em:

http://africultures.com/le-pluriethnisme-est-une-richesse-si-lesgens-nont-pas-honte-de-parler-leur-langue-3101/. Acesso em: 21 jan. 2021.

CALIL, Carlos Augusto. "Preto no Branco". In: CENDRARS, Blaise. Pequenos contos negros. Ilustrações Lygia Rocco, tradução Priscila Figueiredo. São Paulo: Edições SM, 2014, p. 7-13.

COTTIER, Christine Le Quellec. "Blaise Cendrars et Carl Einstein”. In: WAGNER, Birgit. CHEMINEAU, Manuel. Fenille de routes. Bulletin de L'Association Internationale Blaise Cendrars. $n^{\circ}$ 52, automne 2014.

DERRIDA, Jacques. Gramatologia. Tradução Miriam Chnaiderman e Renato Janine Ribeiro. São Paulo: Perspectiva, 2004.

EINSTEIN, Carl (editor). Afrikanische Märchen und Legenden. Bremen: ELV, 2013.

EINSTEIN, Carl. Afrikanische Märchen und Legenden. Hamburg: Fischer Taschenbuch Verlag, 2014.

EINSTEIN, Carl. Documents: 1929 / Carl Einstein; tradução Takashi Wakamatsu. Desterro [Florianópolis]: Cultura e Barbárie, 2016.

ÉLOI, Ficquet et GALLIMARDET, Lorraine, "On ne peut nier longtemps l'art nègre”, Gradhiva, 10, 2009. Disponível em : http://journals.openedition.org/gradhiva/1560.

EULALIO, Alexandre. A Aventura brasileira de Blaise Cendrars: ensaio, cronologia, filme, depoimentos, antologia, desenhos, conferência, correspondência, traducões / Alexandre Eulalio. - 2. Ed. rev. e ampl. por Carlos Augusto Calil. São Paulo: Editora da USP : Fapesp, 2001.

GOMES, Laurentino. "Infelizmente, a história da escravidão é contada por pessoas brancas". In: DMT, de 04.12.2019. Disponível em:

http://www.dmtemdebate.com.br/laurentino-gomes-infelizmente-a-historia-da-escravidao-e-contada-por-pessoas-brancas/. Acesso em: 21 jan. 2021.

22 Em 1966, o Premier Festival mondial des arts nègres de Dakar com o tema "On ne peut nier longtemps l'art nègre" [não se pode negar mais a arte negra] foi uma imensa manifestação artística internacional organizada no continente África, que promoveu a arte africana de maneira inédita. Pode-se dizer que Léopold Sédar Senghor e seus colegas perfizeram uma segunda frente da "negritude". ÉLOI, Ficquet et GALLIMARDET, Lorraine, “On ne peut nier longtemps l'art nègre”, 2009, s/p. 
GUIMARÃES, Ruth. Contos negros. São Paulo: Faro editorial, 2020.

HAUSENSTEIN, Wilhelm. "Negerplastik”. In: MÄRZ. Eine Wochenzeitschrift. 9 1915, Band 3-4. p. 102-104. Disponível em: archiv.org. Acesso em: 07 set. 2020.

HUEBNER, Friedrich Markus. "Und Afrika sprach”. In: Die Schaubühne, 11 (1915), p. 458-9. Disponível em archiv.org Acesso em 07/09/2020.

KIEFER, Klaus H. Diskurswandel Im Werk Carl Einsteins. Ein Beitrag zur Theorie und Geschichte der europäischen Avantgarde. Tübingen 1994. Überarbeitete Fassung, 2015.

LÉVI-STRAUSS, Claude. Tristes Trópicos. Tradução de Wilson Martins. São Paulo: Editora ANHEMBI LIMITADA, 1957.

MARQUES, Ivan. Modernismo em Revista - Estética e Ideologia nos periódicos dos anos 1920. Rio de Janeiro: Casa da Palavra, 2013.

MBEMBE, Achille. Crítica da ražão negra. Tradução de Sebastião Nascimento. São Paulo: N-1 Edições, 2018.

MEINHOF, Carl. Afrikanische Märchen. Jena: Diederichs, 1921.

MEINHOF, Carl. Die Christianisierung der Sprachen Afrikas. Basel: Bassler Missionsstudien, 1905.

MEMMI, Albert. Retrato do colonizado precedido do retrato do colonizador. Tradução de Marcelo Jacques de Moraes, Rio de Janeiro: Civilização Brasileira, 2007.

RAUTERBERG, Hanno. “Ab ins Museum!”. In: Die Zeit, 20. August 2020.

ROLAND, Hubert. Die deutsche literarische "Kriegskolonie" in Belgien, 1914-1918. Bern; Berlin; Frankfurt/M.; New York; Paris; Wien: Lang, 1999.

ROTHENBERG, Jerome. Etnopoesia no milennio. Tradução de Luci Collin. Rio de Janeiro: Azougue Editorial, 2006.

Submissão: $13 / 05 / 2020$

Aceite: $30 / 09 / 2020$

https://doi.org/10.5007/2176-8552.2021.e84483Esta obra foi licenciada com uma Licença Creative Commons Atribuição-NãoComercial 4.0 Internacional. 